\title{
Uso de Gemas de Ovos de Aves Hiperimunizadas Contra Escherichia coli Suína no Controle da Diarréia Neonatal de Leitões
}

\author{
Andréa Machado Leal Ribeiro ${ }^{1}$, Liliane Rudnik ${ }^{2}$, Cláudio Wageck Canal ${ }^{3}$, Lilian Ribeiro Kratz ${ }^{4}$, \\ Carolina Farias ${ }^{5}$
}

\begin{abstract}
RESUMO - Foi avaliado o efeito das gemas de ovos de aves hiperimunizadas contra Escherichia coli (E. coli) patogênica para suínos sobre a imunidade passiva de leitões recém-nascidos em uma unidade produtora de leitões. Foram avaliados a densidade ótica do ELISA (DO) para anticorpos contra E. coli, o peso corporal e a ocorrência de diarréia diária em 137 leitões recém-nascidos oriundos de 25 fêmeas primíparas, não vacinadas contra $E$. coli. As porcas foram consideradas blocos. De cada fêmea, foram separados seis leitões recém-nascidos de ambos os sexos, excluindo-se os mais leves e os mais pesados, divididos em três tratamentos e duas repetições. Os seguintes tratamentos foram fornecidos via oral: T1: $2 \mathrm{~mL}$ de PBS (tratamento controle) em duas doses, a primeira ao nascer e a segunda duas horas após; T2: $2 \mathrm{~mL}$ de gemas de ovos com título de 100.000 anticorpos contra E. coli (IgY) em duas doses, conforme o tratamento 1; T3: idem ao T2, além de $2 \mathrm{~mL}$ de gema de 3 em 3 dias até os leitões completarem 12 dias de idade. Foram realizadas duas coletas de sangue de 1 leitão/ tratamento/porca: a primeira às 24 horas e a segunda aos 14 dias de idade dos leitões. A IgY contra E. coli dos soros foi analisada por ELISA. A DO do ELISA dos leitões de T2 e T3 foi significativamente maior às 24 horas e aos 14 dias que dos animais do tratamento controle. T3, T2 e T1 permaneceram 87, 79 e 73\% do tempo estudado sem diarréia. Os animais de T3 foram significativamente mais pesados que os do T1, mas não diferiram dos do T2. Os resultados deste estudo sugerem que o uso de gemas de aves hiperimunizadas contra $E$. coli age efetivamente na prevenção da diarréia dos leitões e seu uso contínuo é mais vantajoso que o fornecimento somente ao nascer.
\end{abstract}

Palavras-chave: diarréia, Escherichia coli, gema, Imunoglobulina Y, imunidade passiva, leitões

\section{Supply of Hipperimmunized Hen Yolks against Swine Escherichia coli to Control Newborn Piglets Diarrhea}

\begin{abstract}
The effect of yolks from birds hipperimmunized birds against Escherichia coli (E. coli) pathogenic for swine on the passive immunity of newborn piglets in a producer unit of piglets was studied. It was evaluated ELISA optical density (OD) of antibodies against $E$. coli, body weight and the frequency of diarrhea $(\mathrm{FcD})$ in 137 newborn piglets born from 25 primiparous gilts non-vaccinated against $E$. coli. The gilts were considered blocks. From each gilt, six piglets from both sexes were separated, excluded the lighter and the heavier ones, and divided into three treatments and two replications. The treatments were supplied orally, as follows: T1: $2 \mathrm{~mL}$ of PBS (control treatment) in 2 doses, the first was given at birth and the second 2 hours later; T2: $2 \mathrm{~mL}$ of yolks with titer of 100,000 of antibodies (IgY) against $E$. coli in the same two doses; T3: equal to T2, followed by $2 \mathrm{~mL}$ of yolks every 3 days until piglets reached 12 days old. Old two blood samples were collected from 1 piglet/treatment/gilt: 24 hours after birth and when piglets were 14 days old. The ammount of IgY against $E$. coli in the serum of piglets was also determined by ELISA. The OD for T2 and T3 was significantly higher in the first 24 hours and 14 days after birth compared to the control. T3, T2 and T1 remained 87, 79 and 73\% of the studied period without diarrhea. Due to the lower FcD percentage, T3 piglets were significantly heavier than T1, but did not differ from T2. The results of this study pointed out that the supply of hipperimmunized hen yolks against $E$. coli acts effectively in diarrhea prevention and that the continuous supply is more effective than the supply only at birth.
\end{abstract}

Key Words: diarrhea, Escherichia coli, yolk, immunoglobulin Y, passive immunity, piglets

\section{Introdução}

A Escherichia coli enterotoxigênica (ETEC) é o agente causador de diarréias nos períodos neonatal e imediatamente posterior ao desmame de leitões
(Martineau et al., 1995). A ETEC adere ao epitélio intestinal, produzindo enterotoxinas que ocasionam mudanças do fluxo de água e eletrólitos no intestino delgado, resultando em diarréia (Marquardt et al., 1999). Leitões de leitegadas com diarréia pesaram

\footnotetext{
${ }^{1}$ Professora Adjunto do Departamento de Zootecnia- UFRGS. Av. Bento Gonçalves, 7712, Agronomia - CEP: $91540-000$ (aribeiro@ufrgs.br) Bolsista do CNPq.

2 Zootecnista, aluna de mestrado do PPG-Zootecnia, UFRGS. Bolsista CAPES (lilianerudnik@hotmail.com).

${ }^{3}$ Professor Adjunto do Departamento de Medicina Animal da UFRGS (claudio.canal@ufrgs.br).

${ }^{4}$ Aluna de doutorado do PPG-Zootenia - UFRGS. Bolsista CAPES.

${ }^{5}$ Aluna de graduação de Medicina Veterinária - UFRGS.
} 
cerca de $0,4 \mathrm{~kg}$ a menos aos 30 dias de idade que leitões de leitegadas sem diarréia (Martineau et al., 1995). Para se evitar a queda no desempenho dos animais, o setor de produção animal faz uso constante de vários antimicrobianos em doses subclínicas, tornando-se líder mundial de consumo desses produtos, que constituem fonte de risco à saúde pública (Bellaver, 2000). As imunoglobulinas presentes na gema de ovos de galinhas (IgY) imunizadas com patógenos infecciosos têm demonstrado eficiência na prevenção de infecções, pois são efetivas na inibição da adesão da ETEC in vitro em células do intestino delgado de leitões recém-nascidos (Sugita-Konishi et al., 1996). As IgY são identificadas no soro de leitões recém-nascidos duas horas após sua administração e seu pico de concentração ocorre 24 horas após a ingestão da IgY, gradualmente diminuindo em um período de 21 dias, uma vez que sua meia-vida é de 1,85 dias (Yokoyama et al., 1993). As IgY agem efetivamente na terapia e profilaxia de leitões recém-nascidos infectados com ETEC, podendo ser usadas como fonte de anticorpos de baixo custo contra doenças infecciosas (Zúñiga et al., 1997). No presente trabalho, objetivou-se quantificar as imunoglobulinas Y no soro dos leitões recém-nascidos após a ingestão de gemas de ovos (IgY) de aves hiperimunizadas, verificar distintos padrões de fornecimento das gemas (ao nascer e de 3 em 3 dias até 12 dias) e seu efeito na incidência de diarréia e no ganho de peso.

\section{Material e Métodos}

O estudo foi conduzido em uma unidade produtora de leitões, do período do nascimento até os 14 dias de idade dos leitões. Foram selecionadas 25 fêmeas (Dalland) primíparas não-vacinadas contra Escherichia coli e, de cada fêmea, foram utilizados seis leitões recém-nascidos de ambos os sexos, totalizando 175 animais, dos quais 137 foram utilizados para o experimento, em função de mortalidade inicial, para peso inicial (PI) e densidade ótica do ELISA (DO) e, desse total, 74 leitões para peso aos 7 dias (P7), peso aos 14 dias (P14) e ocorrência de diarréia, em função de descartes ocorridos no processo. Utilizou-se delineamento de blocos ao acaso, considerando-se as marrãs como blocos, cada uma recebendo três tratamentos e duas repetições.

Os ovos de aves hiperimunizadas foram obtidos do trabalho de Kindlein (2002), que vacinou galinhas de postura, via intramuscular, com $0,5 \mathrm{~mL}$ de uma bacterina comercial contra Escherichia coli suína, contendo cerca de $10^{9}$ células bacterianas $/ \mathrm{mL}$. A bacterina administrada às aves foi produzida a partir de seis sorotipos de $E$. coli relacionados à colibacilose suína (K12:K88ab; O157:K88ac; O8:K87:K88ad; 987P; O101:K30:F41; K99). As gemas utilizadas, com título de anticorpos (IgY) de 100.000, foram armazenadas em alíquotas de $30 \mathrm{~g} \mathrm{a}-5^{\circ} \mathrm{C}$, in natura, e, minutos antes do fornecimento aos leitões, foram descongeladas e diluídas em 15 mL de solução tampão (PBS). Foram fornecidas via oral, conforme os tratamentos: T1: $2 \mathrm{~mL}$ de PBS (tratamento controle) em duas doses, a primeira ao nascer e a segunda duas horas após o nascimento; T2: $2 \mathrm{~mL}$ de gema de ovo em ao nascer e duas horas após o nascimento; T3: $2 \mathrm{~mL}$ de gema de ovo ao nascer e duas horas após o nascimento e $2 \mathrm{~mL}$ de gema a cada dias até os leitões completarem 12 dias de idade. Após a primeira dose de gema, o leitão foi colocado junto à mãe para ingerir o colostro materno.

Foram realizadas duas coletas de sangue em 1 leitão/tratamento/porca, a primeira coleta 24 horas após a administração da segunda dose de gema e a segunda, aos14 dias de idade. Após cada coleta, as amostras de sangue foram deixadas nas seringas por uma hora em temperatura ambiente, a fim de facilitar a coagulação. $O$ soro resultante foi centrifugado a $2.000 \mathrm{rpm}$ durante 10 minutos e armazenados em tubos tipo Eppendorf de 1,5 mL, identificados e conservados a $-5^{\circ} \mathrm{C}$, para posterior análise. A ocorrência de diarréia foi observada individualmente por leitão, diariamente, no período da manhã, adotando-se uma classificação simples: com ou sem diarréia. Foi considerada como diarréia, a presença de fezes aquosas a pastosas e de coloração branco-amarelada no ânus do animal. Após persistência de diarréia por dois dias consecutivos, os leitões foram medicados com um antimicrobiano, a fim de se evitar maiores perdas econômicas para a granja.

O título de imunoglobulinas nas gemas e a DO do ELISA contra $E$. coli nos soros dos leitões foram determinados por um ELISA indireto, conforme o seguinte protocolo: foram adicionados às placas de ELISA $100 \mathrm{~mL}$ da diluição da suspensão inativada de Escherichia coli em tampão de sensibilização $(0,1 \mathrm{M}$ Na-carbonato $\mathrm{pH} 9,6$ ), que foram incubadas em câmara úmida a $4^{\circ} \mathrm{C}$, por 16 horas. As placas foram lavadas três vezes com $150 \mathrm{~mL}$ por poço de tampão 
de lavagem (PBS pH 7,2; 0,05\% Tween 20;5\% de leite em pó desnatado Molico, Nestlé). O bloqueio foi realizado com tampão de lavagem por uma hora à temperatura ambiente. Posteriormente, o tampão foi desprezado, adicionando-se $100 \mathrm{~mL}$ das amostras de gema ou soro a serem testadas, que foram diluídos 10 vezes, a começar pela diluição 1:10 até 1:1.000.000 em tampão de lavagem por uma hora à temperatura ambiente. As placas foram lavadas três vezes com $150 \mathrm{~mL}$ de tampão de lavagem. Foram adicionados $100 \mathrm{~mL}$ de solução do conjugado (anti-IgY de galinha conjugado à peroxidase - Kirkegaard Perry Labs. Inc) diluído 1:500 em $100 \mathrm{~mL}$ de tampão de lavagem acrescido de soro normal suíno por uma hora à temperatura ambiente. As placas foram lavadas três vezes com $150 \mathrm{~mL}$ por poço de tampão de lavagem sem leite em pó (PBS pH 7,2; 0,05\% Tween 20). A reação foi revelada por trinta minutos com $100 \mathrm{~mL}$ por poço de uma solução com $3,4 \mathrm{mg}$ de OPD (sfenilenodiamino) e $20 \mathrm{~mL}$ de $\mathrm{H}_{2} \mathrm{O}_{2} 30$ volumes em 10 $\mathrm{mL}$ de tampão citrato-fosfato $0,1 \mathrm{M} \mathrm{pH} \mathrm{5,0}$ (preparado recentemente) e bloqueada com $50 \mathrm{~mL}$ por poço de uma solução de $\mathrm{H}_{2} \mathrm{SO}_{4} 12,5 \%$. A densidade ótica (absorbância) do teste foi determinada 15 minutos após o bloqueio em espectrofotômetro com filtro de $490 \mathrm{~nm}$.

A análise estatística para DO e pesos foi realizada pelo ANOVA, a comparação de médias entre tratamentos pelo Lsmeans e a avaliação da ocorrência de diarréia, pelo teste do qui-quadradro do pacote estatístico SAS (1998). Para a ocorrência de diarréia, contrastes entre os tratamentos (dois a dois) também foram realizados.

\section{Resultados e Discussão}

Os leitões dos três tratamentos não apresentaram diferenças significativas no PI $(\mathrm{P} \leq 0,31)$ e no $\mathrm{P} 7$ $(\mathrm{P} \leq 0,69)$ (Tabela 1). O uso das marrãs como blocos para o controle das variações de PI, P7 e P14 possibilitou controlar as variações do peso dos leitões, de modo que foram observadas diferenças entre blocos nas três pesagens $(\mathrm{P} \leq 0,0001)$. Para PI, a ausência diferenças entre tratamentos era esperada, uma vez que foram escolhidos leitões irmãos com peso similar. Aos 14 dias, os leitões que receberam doses contínuas de gema (T3) alcançaram peso médio de $3,81 \mathrm{~kg}$, diferindo significativamente dos leitões controle (T1), com peso médio de $3,39 \mathrm{~kg}(\mathrm{P} \leq 0,08)$. Os leitões que receberam gema somente ao nascer (T2 - peso médio de 3,64 kg) não apresentaram diferenças estatísticas quando comparados aos dos demais tratamentos. $\mathrm{O}$ peso corporal pode estar diretamente relacionado à menor porcentagem de dias sem diarréia dos leitões do T3 (Figura 1), como nos trabalhos de Marquardt et al. (1999), ao demonstrarem que leitões desafiados com E. coli $\mathrm{K} 88$ sofreram perda de peso de 106 a 182 g 24 horas após o fornecimento, enquanto os não-desafiados apresentaram ganho de $191 \mathrm{~g}$, fato atribuído à diarréia. Neste experimento, os leitões tratados com $0,5 \mathrm{~g}$ de gemas com título de anticorpos contra E. coli de

Tabela 1 - Peso corporal médio dos leitões no início (PI), aos 7 (P7) e 14 dias (P14) do experimento

Table 1 - Piglets average body weight at the beginning (PI), at 7 (P7) and 14 days old (P14)

\begin{tabular}{lccl}
\hline $\begin{array}{l}\text { Tratamento } \\
\text { Treatment }\end{array}$ & PI & P & P14 \\
\hline${ }^{1} \mathrm{~T} 1$ & $1,38 \pm 0,02$ & $2,22 \pm 0,06$ & $3,39 \pm 0,13 \mathrm{~b}$ \\
${ }^{2} \mathrm{~T} 2$ & $1,34 \pm 0,02$ & $2,24 \pm 0,06$ & $3,64 \pm 0,12 \mathrm{ab}$ \\
${ }^{3} \mathrm{~T} 3$ & $1,38 \pm 0,02$ & $2,30 \pm 0,06$ & $3,81 \pm 0,18 \mathrm{a}$ \\
$\mathrm{CV}$ & 10,99 & 12,85 & 16,49 \\
${ }^{5} \mathrm{p}$ & 0,31 & $\leq 0,69$ & $\leq 0,08$ \\
\hline
\end{tabular}

Médias nas colunas seguidas de letras distintas diferem significativamente $(\mathrm{P} \leq 0,08)$.

Means in columns followed by different letters are statistically different (PS.08).

${ }^{1}$ Controle, ${ }^{2}$ Gema ao nascer, ${ }^{3}$ Gema ao nascer e a cada três dias.

${ }^{1}$ Control treatment, ${ }^{2}$ Yolk at birth, ${ }^{3}$ Yolk at birth and every three days.

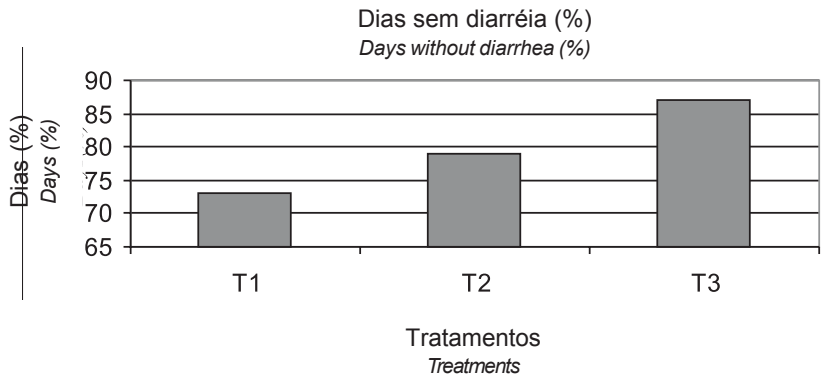

Comparação entre os tratamentos T1, T2 e T3 fol significativa $(P \leq 0,0001)$.

Comparison among T1, T2, and T3 was significant $(P \leq 0.0001)$.

Figura 1 - Valores percentuais de dias sem ocorrência de diarréia no período experimental 14 dias.

Figure 1 - Percentual values of days without diarrhea during the experimental period (14 days). 
Tabela 2 - Valores médios e desvio-padrão da densidade ótica (DO) do ELISA no $1^{\circ}$ e $14^{\circ}$ dias de vida dos leitões

Table 2 - Average values and standard errors for ELISA optical density $(O D)$ of piglets at $1^{\text {st }}$ and $14^{\text {th }}$ days old

\begin{tabular}{lcc}
\hline $\begin{array}{l}\text { Tratamento } \\
\text { Treatment }\end{array}$ & DO $(1$ dia $)$ & DO $(14$ dias $)$ \\
\hline${ }^{2} \mathrm{~T} 1$ & $0,1630 \pm 0,061 \mathrm{~b}$ & $0,2680 \pm 0,005 \mathrm{~b}$ \\
${ }^{3} \mathrm{~T} 2$ & $1,2112 \pm 0,063 \mathrm{a}$ & $0,2838 \pm 0,005 \mathrm{a}$ \\
${ }^{4} \mathrm{~T} 3$ & $1,1894 \pm 0,062 \mathrm{a}$ & $0,2919 \pm 0,005 \mathrm{a}$ \\
$\mathrm{CV}$ & 37,04 & 8,51 \\
$\mathrm{P}$ & $\leq 0,0001$ & $\leq 0,01$ \\
\hline
\end{tabular}

Médias nas colunas seguidas de letras diferentes diferem significativamente $(P \leq 0,01)$.

Mean in column followed by different letters are statistically different $(P \leq 0.01)$.

${ }^{1}$ Controle, ${ }^{2}$ Gema ao nascer, ${ }^{3}$ Gema ao nascer e de 3 em 3 dias.

${ }^{1}$ Control treatment, ${ }^{2}$ Yolk at birth, ${ }^{3}$ Yolk at birth and every three days.

140.000, três vezes ao dia, por dois dias, se recuperaram e ganharam peso. Marquardt et al. (2000) desafiaram leitões de 21 dias de idade, por duas vezes, com $10^{12}$ UFC de K88 e trataram-nos com $50 \mathrm{mg}$ de gemas (IgY) por três vezes no dia do desafio e durante dois dias consecutivos antes do desafio e observaram que os animais controle perderam $36 \mathrm{~g}$, ao passo que aqueles que receberam gemas tiveram ganho de peso de $91 \mathrm{~g}$ no período de três dias.

Considerando-se os resultados da quantificação de IgY contra E. coli nos soros por meio de ELISA (Tabela 2), observa-se que houve diferença estatística significativa da DO nos soros dos leitões 24 h após a administração das gemas nos tratamentos 2 e 3 em relação ao controle $(\mathrm{P} \leq 0,0001)$. Aos 14 dias de idade, ainda foi verificada DO do ELISA maior em T2 e T3 em relação ao controle, ainda que os valores fossem menores do que na primeira determinação. Este resultado confirma outros estudos que comprovaram que a máxima absorção de imunoglobulinas ocorreu de 4 a $12 \mathrm{~h}$ após o primeiro aleitamento (Westrom et al., 1985), quando foram absorvidas no epitélio do jejuno (Holland, 1990). De 24 a 48 horas após o nascimento, as paredes intestinais já estão fechadas para a absorção de macromoléculas e o fornecimento contínuo das gemas agiria na imunidade local, sem absorção pelos vasos linfáticos, o que o fato de os leitões do T3, apesar de estarem recebendo doses contínuas de gemas, não diferiram estatisticamente dos valores de DO do T2.
Resultados semelhantes foram encontrados por Yokoyama et al. (1993). Em leitões que receberam gemas de ovos 10 horas após o nascimento, as IgY puderam ser identificadas no soro $2 \mathrm{~h}$ após a administração oral, com pico de concentração 24 h após a administração. Quando as gemas foram administradas 34 horas após o nascimento, não houve detecção de $\mathrm{IgY}$, indicando falta de permeabilidade do trato gastrintestinal para essas macromoléculas. Após o pico de IgY, sua concentração no soro foi diminuindo gradualmente até os 21 dias, uma vez que sua meia vida é de 1,85 dias, portanto menor que a meia-vida da $\mathrm{IgG}$ do colostro, que é de 12 a 14 dias (Curtis et al., 1973). A IgY é menos rígida e mais instável em $\mathrm{pH}$ baixo que a IgG e a passagem da molécula pelo estômago pode afetar a sua estabilidade mais rapidamente que na IgG dos mamíferos (Schmidt et al., 1989).

Quanto à diarréia, foram observadas diferenças significativas em função do tratamento fornecido aos leitões $(\mathrm{P} \leq 0,0001)$. Os leitões de T1 e T2 permaneceram 73 e $79 \%$ do tempo estudado sem diarréia, respectivamente (Figura 1). Comparados ao controle, os leitões de T3 passaram menos dias sem diarréia ( $87 \%$ do período) $\left(\mathrm{P} \leq \mathrm{X}^{2}<0,0001\right)$, o que indica que as imunoglobulinas não só agiram imunizando sistemicamente os animais como também no trato digestivo dos animais que receberam gemas em doses contínuas (Figura 1).

A comparação do tratamento controle (T1) e T2 por análise de contrastes comprovou que os leitões do segundo grupo permaneceram significativamente menos dias sem diarréia $(\mathrm{P} \leq 0,04)$. A imunidade passiva dos leitões do T2 confirma os estudos de Zúñiga et al. (1997), que desafiaram leitões desmamados de 23 a 30 dias, com E. coli de fímbrias F18ab e F18ac e verificaram que o consumo de 5,5 g de ovo liofilizado adicionado à ração foi suficiente para diminuir a quantidade de bactérias presentes nas fezes. Resultados semelhantes foram obtidos por Imberechts et al. (1997), ao verificarem in vitro que anticorpos contra fímbrias F18ab inibiram a adesão da bactéria na parede intestinal.

O contraste do tratamento controle com o T3 indicou que os leitões que receberam gemas de forma contínua permaneceram por mais dias sem diarréia $(\mathrm{P} \leq 0,0001)$. Os resultados comprovam a efetividade do efeito profilático, mas também sugerem um efeito terapêutico da gema, proposto por Yokoyama et al. 
(1992) e Wiedemann et al. (1991). O contraste entre o tratamento T2 e o T3 mostrou que o último proporcionou, significativamente, menos dias sem diarréia aos leitões $(\mathrm{P} \leq 0,006)$.

Resultados de Yokoyama et al. (1992) validaram, além do efeito profilático, também o efeito terapêutico da $\operatorname{IgY}$, ao desafiarem leitões quatro horas após o nascimento com $10^{12} \mathrm{UFC}$ de E. coli com fímbrias K88, K99 e 987P e, somente após a ocorrência da diarréia, forneceram $4 \mathrm{~mL}$ de gemas purificadas e liofilizadas três vezes ao dia. A diarréia cessou de dois a três dias após o tratamento, com os melhores resultados naqueles leitões que receberam gema com anticorpos específicos para as fímbrias acima citadas, com título de 2500. Wiedemann et al. (1991), trabalhando em granjas com alta incidência de diarréia, forneceram $4 \mathrm{~g}$ de gemas liofilizadas com título de anticorpos de 9840 contra K88ac, administradas oralmente por três a cinco dias e verificaram que $43 \%$ dos leitões foram curados após o primeiro dia, $41 \%$ no segundo e $6 \%$ no terceiro, enquanto o grupo controle permaneceu com diarréia.

Ao analisar o percentual de leitões que necesitaram de medicação em razão da persistência da diarréia por mais de dois dias, foram observadas diferenças estatísticas entre os tratamentos $(\mathrm{P} \leq 0,015)$ (Tabela 3$)$. Houve incidência de diarréia em $4 \%$ dos leitões de T1 e T2 e de apenas $0,6 \%$ nos leitões do tratamento T3.

Tabela 3 - Freqüência observada e esperada ( ) e porcentagem de leitões com e sem diarréia durante os 14 dias do período experimental, classificados em função do recebimento ou não de medicação

Table 3 - Frequency observed and expected( ) and percentage of piglets with and without diarrhea during the 14 days of experimental period classified as receiving medication support or not

\begin{tabular}{|c|c|c|c|c|c|}
\hline \multirow{3}{*}{$\begin{array}{l}\text { Tratamento } \\
\text { Treatment }\end{array}$} & \multirow{2}{*}{\multicolumn{2}{|c|}{$\begin{array}{l}\text { Sem medicação } \\
\text { Without medication }\end{array}$}} & \multirow{2}{*}{\multicolumn{2}{|c|}{$\begin{array}{l}\text { Com medicação } \\
\text { With medication }\end{array}$}} & \multirow{3}{*}{$\begin{array}{l}\text { Total } \\
\text { Total } \\
\end{array}$} \\
\hline & & & & & \\
\hline & $\begin{array}{l}\text { Leitões x dias } \\
\text { Piglets } x \text { days }\end{array}$ & $\%$ & $\begin{array}{l}\text { Leitões x dias } \\
\text { Piglets } x \text { days }\end{array}$ & $\%$ & \\
\hline${ }^{1} \mathrm{~T} 1$ & $308(312,07)$ & 96 & $13(8,92)$ & 4 & 321 \\
\hline${ }^{2} \mathrm{~T} 2$ & $351(353,88)$ & 96 & $13(10,12)$ & 4 & 364 \\
\hline${ }^{3} \mathrm{~T} 3$ & $320(313,05)$ & 99,4 & $2(8,95)$ & 0,6 & 322 \\
\hline $\bar{P}$ & \multicolumn{4}{|c|}{$\leq 0,015$} & \\
\hline
\end{tabular}

\section{Conclusões}

As IgY fornecidas oralmente por meio de gema de ovos de aves hiperimunizadas contra E. coli suína foram absorvidas eficientemente nas primeiras horas após o nascimento de leitões. Após esse período, o fornecimento de gemas exerceu um efeito terapêutico no controle da diarréia, embora não houvesse mais absorção intestinal. Os resultados permitem inferir que o fornecimento contínuo de gemas é mais vantajoso que o fornecimento somente ao nascer, tanto para prevenir diarréia quanto para se obter melhores ganhos de peso, diminuindo o uso de antimicrobianos em leitões recém-nascidos.

\section{Agradecimento}

À Doux Frangosul, pela disponibilização dos animais e das instalações, que tornaram este trabalho viável. Ao professor David Barcellos, Faculdade de Veterinária, UFRGS, pelas informações fundamentais para a execução deste trabalho e pelo treinamento para as coletas de sangue.

\section{Literatura Citada}

BELLAVER, C.O uso de microingredientes (aditivos) na formulação de dietas para suínos e suas implicações na produção e na segurança alimentar. In: Encontros Técnicos AbravesSC, p.56-76, 2000. 
CURTIS, J.; BOURNE, F.J. Half-lives of immunoglobulins IgG, $\operatorname{IgA}$ and $\operatorname{IgM}$ in the serum of new-born pigs. Immunology, v.24, p.147-155, 1973.

HOLLAND, R.E. Some infectious causes of diarrhea in young farm animals. Clinical Microbiology Reviews, v.3, p.345-375, 1990.

IMBERECHTS, H.; DEPREZ, P.; DRIESSCHE, E.V. et al. Chicken egg yolk antibodies against F18ab fimbrae of Escherichia coli inhibit shedding of F18 positive E. coli by experimentally infected pigs. Veterinary Microbiology, v.54, p.329-341, 1997.

KINDLEIN, G. A influência da alimentação com diferentes níveis de vitamina $\mathrm{E}$ sobre a produção de imunoglobulina Y (IgY) no soro de poedeiras leves. Porto Alegre: Universidade Federal do Rio Grande do Sul, 2002. 94p. Dissertação (Mestrado em Produção Animal) - Universidade Federal do Rio Grande do Sul, 2002.

MARTINEAU, G.P.; VAILLANCOURT, J.P.; BROES, A. Principal neonatal diseases. In: The neonatal pig development and survival. Québec: CAB International, 1995. p.239-268.

MARQUARDT, R.R.; JIN, L.Z.; KIN, J. et al. Passive protective effect of egg-yolk antibodies against enterotoxigenic Escherichia coli $\mathrm{K} 88+$ infection in neonatal and early-weaned piglets. Fems Immunology and Medical Microbiology, v.23, n.4, p.283-288, 1999.

MARQUARDT, R.R. Control of intestinal diseases in pigs by feeding specific chicken egg antibodies. In: CAB Publishing (Ed.) Egg nutrition and biotechnology. Winnipeg: CAB International, 2000. p.289-299.

SCHMIDT, P.; WIEDEMANN, V.; KUHLMANN, R. et al. Chicken egg antibodies for prophylaxis and therapy of infectious intestinal diseases. II. In vivo studies on gastric and enteric digestion of egg yolk antibodies specific against pathogenic Escherichia coli strains. Journal of Veterinary Medicine B, v.36, p.619-628, 1989.

SUGITA-KONISHI, Y.S.; SHIBATA,K.; YUN, S.S. et al. Immune functions of immunoglobulin Y isolated from egg yolk of hens immunized with various infectious bacteria. Bioscience Biotechnology and Biochemistry, v.60, n.5, p.886-888, 1996 .
YOKOYAMA, H.; PERALTA, R.C.; DIAZ, R. et al. Passive protection of chicken egg yolk immunoglobulins against experimental enterotoxigenic Escherichia coli infection in neonatal piglets. Infection and Immunity, v.60, n.3, p.998-1007, 1992.

YOKOYAMA, H.; PERALTA, R.C.; DIAZ, R. et al. Detection of passage and absorption of chicken egg yolk immunoglobulins in the gastrointestinal tract of pigs by use of enzyme-linked immunosorbent assay and fluorescent antibody testing. American Journal of Veterinary Research, v.54, n.6, p.867-872, 1993.

WESTROM, B.R.; OHLSSON, B.G.; SVENDSEN, J. et al. Intestinal transmission of macromolecules (BSA and FITCdextran) in the neonatal pig: enhancing effect of colostrum, proteins and proteinase inhibitors. Biology of the Neonate, v.47, p.349-366, 1985.

WIEDEMANN, V.; LINCKH, E.; KUHLMANN, R. et al. Chicken for prophylaxis and therapy of infectious intestinal diseases. In vivo studies on protective effects against Escherichia coli diarrhea in pigs. Jounal of Veterinary Medicine B, v.38, p.283-291, 1991.

ZÚÑIGA, A.; YOKOYAMA, H.; ALBICKER-RIPPINGER, P. et al. Reduced intestinal colonization with F18-positive enterotoxigenic Escherichia coli in weaned pig fed chicken egg antibody against the fimbrae. Fems Immunology and Medical Microbiology, v.18, n.3, p.153-161, 1997. 